\title{
ТАЙНЫ, КОТОРЫЕ ОКРУЖАЮТ БОЛЕЗНЬ KАWАSАКІ: ОБЗОР ЛИТЕРАТУРЫ
}

\section{ОРИГИНАЛЬНАЯ СТАТЬЯ}

ROSSI, Karoline ${ }^{1}$, MOREIRA, Danilo José Silva ${ }^{2}$, FONSECA, Juliana Brito da ${ }^{3}$, VASCONCELOS, Suzana dos Santos ${ }^{4}$, OLIVEIRA, Vinicius Faustino Lima de ${ }^{5}$, DIAS, Claudio Alberto Gellis de Mattos ${ }^{6}$, OLIVEIRA, Euzébio de ${ }^{7}$, DENDASCK, Carla Viana $^{8}$, ARAÚJO, Maria Helena Mendonça de ${ }^{9}$, FECURY, Amanda Alves ${ }^{10}$

ROSSI, Karoline. Et al. Тайны, которые окружают болезнь Kawasaki: Обзор литературы. Revista Científica Multidisciplinar Núcleo do Conhecimento. Год 06, эд. 04, Vol. 05, стр. 52-64. Апрель 2021 г. ISSN: 2448-0959, Ссылка доступа: https://www.nucleodoconhecimento.com.br/здравоохранение/болезнь-kawasaki,

DOI: 10.32749/nucleodoconhecimento.com.br/ru/82509

\section{СВОДКА}

Болезнь Kawasaki (DK) или синдром слизистой оболочки лимфатических узлов является системным васкулитом, который в основном поражает детей в

\footnotetext{
${ }^{1}$ Медицинский академик. Федеральный университет Amapá (UNIFAP).

${ }^{2}$ Медицинский ученый. Федеральный университет Amapá (UNIFAP).

${ }^{3}$ Медицинский академик. Федеральный университет Amapá (UNIFAP).

${ }^{4}$ Медицинский академик. Федеральный университет Amapá (UNIFAP).

${ }^{5}$ Медицинский ученый. Федеральный университет Amapá (UNIFAP).

${ }^{6}$ Биолог, кандидат теоретических и летных исследований, профессор и исследователь курса химии Института базового, технического и технологического образования Amapá (UNIFAP).

${ }^{7}$ Биолог, доктор философии в области тропических болезней, профессор и исследователь курса физкультуры, Федеральный университет Pará (UFPA).

${ }^{8}$ Богослов, кандидат клинических психоанализов. Он проработал 15 лет с научной методологией (методом исследования) по ориентации научного производства студентов магистратуры и докторантуры. Специалист по маркетинговым исследованиям и исследованиям в области здравоохранения.

${ }^{9}$ Доктор педагогических и медицинских наук, профессор и исследователь медицинского курса кампуса Макапе, Федеральный университет Amapá (UNIFAP).

${ }^{10}$ Биомедицинская, phD в тропических заболеваниях, профессор и исследователь медицинского курса кампуса Макапе, Федеральный университет Amapá (UNIFAP).
}

RC: 82509

Disponível

em: https://www.nucleodoconhecimento.com.br/здравоохранение/болезнь- 
возрасте до пяти лет с азиатским происхождением, но может также достигать других возрастных групп, а также любой другой породы. Клиническая картина DK имеет три стадии: острая фебрильная стадия, в которой конъюнктивальные заторы, оральный мукозит, эритема, шелушение, полиморфная сыпь и боковой лимфаденопатия, появляются в качестве основных симптомов; подогромная стадия, которая происходит в конце лихорадки, и приводит к появлению кожи шелушения в конечностях, артрит, артралгия и тромбоцитоз и, наконец, стадия выздоровления, которая возникает, когда симптомы почти рассеивается и продолжается до их нормализации. Наиболее частое лечение происходит от введения внутривенного иммуноглобулина, который для лучшего прогноза патологии следует начать на ранней стадии.

Ключевые слова: Синдром слизистых лимфатических узлов, Васкулит, Артерит, Лихорадка, Kawasaki.

\section{ЗНАКОМСТВО}

Болезнь Kawasaki (DK) является системным васкулитом, который поражает мелкие и средние сосуды и в основном поражает детей в возрасте до 5 лет, будучи одной из причин сердечных заболеваний в детстве (HUANG et al., 2015; MAGALHÃES, 2008). Этиология DK, то есть причинных агентов этого заболевания, не известны. Тем не менее, некоторые клинические и эпидемиологические аспекты предлагают возможные инфекционные причины (FERRONATO et al., 2010).

DK является вторым наиболее распространенным васкулитом в детском возрасте, затрагивающих в основном детей в возрасте до половины десятилетия (90\%). Это редкость у детей в возрасте до 6 месяцев и старше 8 лет, которые, однако, более склонны к развитию коронарных аневризм. В глобальном масштабе число случаев заболевания несколько раз: Наиболее

RC: 82509

Disponível

em: https://www.nucleodoconhecimento.com.br/здравоохранение/болезнь- 
пострадавшей страной является Япония, где ежегодная заболеваемость составляет от 110 до 150 случаев на 100000 детей в возрасте до 5 лет. учитывая расчет показателей заболеваемости на каждые 100000 детей в возрасте до 5 лет, в Соединенных Штатах Америки (США) DK является наиболее распространенной причиной детских заболеваний сердца, начиная от 9,1 до 32,5 случаев, происходящих чаще всего у потомков азиатских и тихоокеанских островов $(32,5)$, промежуточных среди афроамериканцев $(16,9)$ и испаноязычных $(11,1)$ и необычных у кавказцев $(9,1)$ (ALMEIDA et al., 2010; CASTRO; URBANO; COSTA, 2009; RODRIGUES et al, 2017).

DK имеет более высокую распространенность среди азиатского населения, с акцентом на японском языке, затрагивающих в основном детей. Имеется сообщение о ежегодной заболеваемости в Японии и Корее до 100 случаев на 100000 жителей, в то время как в кавказской расе этот случай составляет от 6 до 10 случаев на 100000 жителей в возрасте до половины десятилетия. В Латинской Америке, по оценкам, на 100000 жителей в расчете на 100000 жителей происходит 3 случая заболевания, что свидетельствует о более низкой частоте этой патологии среди неазиатских групп населения, не являющихся потомки азиатов (SCARDINA et al., 2007). Что касается смертности, связанной с DK, то она очень низкая, так как она составляет менее 0,1\% (BARCA et al., 2019).

Заболеваемость DK варьируется географически в мире, будучи более распространенной среди японских потомков, что свидетельствует о генетической предрасположенности заболевания, в дополнение к возможным причинно-следственных агентов, которые могут быть связаны с географическим положением, таких как бактерии (CASTRO; URBANO; COSTA, 2009; RODRIGUES et al, 2017).

$\mathrm{RC}: 82509$

Disponível

em: https://www.nucleodoconhecimento.com.br/здравоохранение/болезнь- 
Сезонные различия в заболеваемости DK хорошо известны, однако ставки в разных странах меняются. В Великобритании, Австралии и США, есть большее число случаев зимой и весной. В Китае и Корее, весной и летом. В США и Великобритании рост ставок в большей степени коррелирует с изменением дождливых периодов, чем с изменением температуры. В Бразилии исследование, проведенное с участием 70 пациентов с DK, показало более высокий уровень заболеваемости, совпадающий с периодами более высокой заболеваемости инфекционными заболеваниями в период с мая по июнь (начало засухи) и ноябрь и декабрь (ранние дожди) (MAGALHÃES; ALVES, 2017).

У человека с DK развиваются симптоматологические характеристики, которые приводят к представлению клинической картины, которая состоит из набора признаков и симптомов, проявляемых пациентом (KAYIRAN; DINDAR; GURAKAN, 2010).Таким образом, клиническая картина DK характеризуется лимфаденопатией шейки матки, лихорадкой, тонзиллитом, отеком конечностей, сыпью, зудом и шелушением (ATIK, 2007; SCARDINA et al., 2007). Кроме того, DK может вызвать обобщенное воспаление, поражая некоторые органы, вызывая воспалительные кардиомиопатия, стерильный менингит, гепатит, аденолинфит, перикардит и ангит (CASTRO; URBANO; COSTA, 2009).

Castro, Urbano и Costa (2009) указывают на связь между васкулитом, вызванным DK, и вовлечением некоторых органов, которые состоят из группировки тканей, ответственных за поддержание организма.

DK был впервые сообщил в 1967 году японский врач Tomisaku Kawasaki, который определил его как "синдром слизистой лимфатических узлов". За этот период в период с 1961 по 1967 год было зарегистрировано 50 случаев заболевания. В Японии этот показатель выше, а глобальное распределение

RC: 82509

Disponível

em: https://www.nucleodoconhecimento.com.br/здравоохранение/болезнь- 
имеет свою переменную распространенность (ALMEIDA et al., 2010; SCARDINA et al., 2007; MAGALHÃES; ALVES, 2017).

В текущем сценарии уже установлены некоторые эпидемиологические данные по DK, позволяющие более точно анализ фракторов, влияющих на распространение и распространение заболеваний. Многие исследования были проведены для того, чтобы понять патофизиологию болезни, которая состоит из набора аномальных изменений, вызванных в организме (CASTRO; URBANO; COSTA, 2009).

В одном исследовании, доказательства DK и заранее других сопутствующих заболеваний были найдены, что относится к тому, что два или более заболеваний в то же время в человеке, так что осложнения DK будет неблагоприятной эволюции этой ассоциации (SCARDINA и др., 2007).

Для улучшения ухода и качества жизни пациента с DK были разработаны методы лечения, которые состоят из способов ухода за пациентом (CASTRO; URBANO; COSTA, 2009).

\section{ЦЕЛЕЙ}

Подробно о возможных причинных агентах, патофизиологии, основных органах и анатомических структурах, пораженных болезнью Kawasaki (DK).

Проверить основные характеристики клинической картины человека для диагностики, основные связанные с этим осложнения, а также методы лечения, доступные для пациентов с DK.

RC: 82509

Disponível

em: https://www.nucleodoconhecimento.com.br/здравоохранение/болезнь- 


\section{МЕТОД}

Это библиографическое исследование, проведенное в базах данных Scielo, Бразильская цифровая библиотека диссертаций и диссертаций, LILACS и PubMed, используя ключевые слова или их ассоциации: болезнь KawasakiKawasaki.

Параметры включения, используемые при подготовке поисков, были всеобъемлющим доступом в Интернете, прямым подходом к болезни Kawasaki (DK) или по некоторым аспектам, относящимся к этому заболеванию. В базе данных Scielo были текстовые фильтры постановок, написанных на английском и португальском языках, в других базах данных этот критерий не использовался. Применяемые параметры исключения дублировались и выполнялись до 2000 года.

В упомянутых базах данных был проведен анализ статей, связанных с DK, в литературе. Из предыдущего прочтения названий и рефератов найденных научных постановок были отвергнуты исследования, которые не соответствовали тому, что, как ожидалось, представляло собой этот обзор. Были зачитаны полные тексты, которые прошли предыдущие этапы, и был отбор для этого обзора тех, которые касались соответствующих аспектов DK.

\section{РЕЗУЛЬТАТЫ}

\section{ВОЗМОЖНЫЕ ПРИЧИННЫЕ АГЕНТЫ DK}

Причина болезни Kawasaki до сих пор неизвестна. Однако его клинические и эпидемиологические характеристики питают гипотезу о том, что причиной запуска является инфекционное вещество, которое производит изменения в клетках, тканях и органах людей с генетической предрасположенностью. Эта

RC: 82509

Disponível

em: https://www.nucleodoconhecimento.com.br/здравоохранение/болезнь- 
гипотеза является наиболее вероятной, но она до сих пор не имеет доказательств (CASTRO; URBANO; COSTA, 2009).

Одной из теорий является коронавирус NL-63, обнаруженный с помощью полимеразной цепной реакции (PCR) в дыхательных жидкостях 11 пациентов с КД и только у 1 из 22 пациентов с контролем. Тем не менее, еще 5 более поздних исследований не нашли коронавируса в образцах дыхательных или нософраритных тканей у пациентов, что делает невозможным для этого вируса, чтобы быть триггерной причиной (CASTRO; URBANO; COSTA, 2009).

Другая теория заключается в иммунологической стимуляции бактериальными суперантигенами, такими как стафилококковые и стрептококковые токсины. Третья теория иммунологическая, которая предполагает, что DK быть вызваны аномальным иммунным ответом у генетически предрасположенных лиц (MAGALHÃES; ALVES, 2017).

\section{ФИЗИОПАТИЯ DK}

Изменения, обнаруженные в DK, особенно гистологические, характеризуют картину обобщенного системного ангиита, поражающего в основном сосуды среднего калибра, особенно коронарные артерии. В некоторых органах наблюдаются печально известные изменения, например, в миокарде, в перикардии, в кровеносных сосудах, в опоясываниях, в легких, в лимфатических узлах и в печени (CASTRO; URBANO; COSTA, 2009).

\section{ОСНОВНЫЕ АНАТОМИЧЕСКИЕ ОРГАНЫ И СТРУКТУРЫ, ПОРАЖЕНHЫЕ DK}

DK поражает органы и артерии, в основном сосуды среднего калибра из различных систем человеческого организма, таких как сердечно-сосудистая,

RC: 82509

Disponível

em: https://www.nucleodoconhecimento.com.br/здравоохранение/болезнь- 
легочная, желудочно-кишечная (кишечная и желчнокаменной являются основными пораженными органами) и центральной нервной системы (SNC). Тем не менее, следует подчеркнуть, что это заболевание имеет в сердце, с образованием коронарных аневризм (CASTRO; URBANO; COSTA, 2009).

Другие артерии также могут быть затронуты, такие как: аневризма аорты, с большим числом зарегистрированных случаев, компрометирующих брюшной аорты; аневризмы подмыслия артерий; аневризма брахиоцефралической артерии; аневризмы подвздошных артерий, бедренной кости; аневризма почечной артерии и непроходимость глазных артерий (ALVES et al., 2011).

\section{ОСНОВНЫЕ ОСОБЕННОСТИ КЛИНИЧЕСКОЙ КАРТИНЫ ЧЕЛОВЕКА ДЛЯ ДИАГНОСТИКИ DK}

Лихорадка, которая знаменует собой острую фразу заболевания, как правило, повышена (выше 39 градусов по Цельсию) и на пиках, временно уменьшаясь по интенсивности продолжительностью от семи до четырнадцати дней, и может достигать трех и/или четырех недель, если нет надлежащего лечения. День, в который начинается лихорадка, считается первым днем заболевания. Тем не менее, некоторые пациенты имеют другие классические проявления до лихорадки, такие как: нечистый конъюнктивит; увеличение лимфатических узлов; эритемы и/или отеки на руках и ногах; scalartiniform rash (сыпью), morbiliform или полиморфный; малиновый язык, эритема и отек орофраринкса, трещины и покраснение губ (CASTRO; URBANO; COSTA, 2009).

Изменения в конечностях (руках и ногах) с эритемами и/или отеком также появляются в острой фразе, а отек очень болезненный и связан с пальмоплантарной эритемой с васкулитом на кончиках пальцев, что через период от одной до двух недель, уже в подострых фразах, начинает чистить,

RC: 82509

Disponível

em: https://www.nucleodoconhecimento.com.br/здравоохранение/болезнь- 
начиная с периунгеальной области в перчаточном пальце (MAGALHÃES; ALVES, 2017).

Неисчерпаемый двусторонний конъюнктивит особенно влияет на бульбарную конъюнктиву по сравнению с палебральной и смоляной конъюнктивой и безболезненно. Иногда он сопровождается иридоциклитом, воспалением передней части глаза, с быстрым разрешением и мало связан с чувствительностью к свету (CASTRO; URBANO; COSTA, 2009).

Полиморфная сыпь является набор сыпь, которые происходят в первые дни заболевания, в основном затрагивающих ствола и конечностей, без видимых волдырей или пузырьков. Они имеют переменную презентацию (крапивница сыпь, morbiliform, maculopapular) или диффузный, напоминающий скарлатины (ALMEIDA et al., 2010).

Изменения в губах и полости рта 9 из 10 случаев в острой фразе с интенсивной лабораторной и орофраринксной гиперемией, трещинами, сухой слизистой оболочкой и кровотечением губ. Язык сосочных сил может стать заметным и устные язвы с истокато ротограто иногда может наблюдаться. Что касается лимфаденомегалии шейки матки, еще одного диагностического критерия, пациент должен представить по крайней мере один лимфатический узел диаметром больше или равен 1,5 cм, обычно односторонний, болезненный и твердый, в передней шейном треугольнике (ALMEIDA et al., 2010; MAGALHÃES; ALVES, 2017).

\section{ОСНОВНЫЕ ОСЛОЖНЕНИЯ, СВЯЗАННЫЕ С DK}

У пациентов с DK в разные моменты эволюции заболевания высвязаются три типа васкулопатии: некротизирующий артерит, подострый/хронический артерит и светивой миофибробластический пролиферативный васкулит. В острой фразе

RC: 82509

Disponível

em: https://www.nucleodoconhecimento.com.br/здравоохранение/болезнь- 
заболевания выделяется некротизирующий артерит, который имеет свой полный патологический процесс в первые две недели после начала лихорадочного состояния, особенно в коронарных артериях, что может определить образование гигантских аневризм, восприимчивых к развитию тромбоза и разрывов. В подострый фазы, проверяется, что процесс подострый васкулит начинается через 2 недели после начала лихорадки, и может повлиять на все кровеносные сосуды, особенно средний сегмент средних мышечных артерий, таких как коронарные артерии. В хронической фразе заболевания происходит светимое фрибробластическое миопролиферация, связанная с хроническим подострым васкулитом (MAGALHÃES; ALVES, 2017).

Наиболее серьезным осложнением заболевания является коронарный васкулит, с изменениями в коронарных артериях, которые затрагивают 15-20\% пациентов, которые не получают лечения. Эти изменения включают аневризмы, эстазии и стенозы коронарных артерий, ответственных за 2\% смертности (ALMEIDA et al., 2010).

В желудочно-кишечном тракте, есть рвота, диарея, боли в животе и паралитический ил. В начале лихорадки, наиболее частыми проявлениями являются рвота и диарея и наименее распространенными являются желтуха, болезненные гепатомегалии, панкреатит, и гидропиковых пузырьков. В дыхательной системе наиболее частыми проявлениями являются кашель, пневмонит и радиологические изменения. Редко встречается риноррея (MAGALHÃES; ALVES, 2017).

B SNC болезнь может проявляться с крайней раздражительностью в острой фазе, помимо асептического менингита, атаксии, паралича лица и сенсорной потери слуха. Также следует отметить наличие ганглия и неврита в черепных и периферических нервах, эндартерит, периартерит, хориомерингит и лептоменингит, в дополнение к атрофии, дегенерации с потерей нейронов,

RC: 82509

Disponível

em: https://www.nucleodoconhecimento.com.br/здравоохранение/болезнь- 
маргинальный и субпендимальный глиоз и образование глиальных узелков вокруг дегенерации нейронов (MAGALHÃES; ALVES, 2017).

Поведенческие изменения, такие как ухудшение зрения, дефицит обучения, эмоциональные изменения (эмоциональная носимость, страх и ночной террор) и проблемы интернализации (тревожное, депрессивное и агрессивное поведение) были описаны в литературе (ALVES et al., 2011).

\section{ЛЕЧЕНИЕ ДЛЯ ЛИЦ, ПОСТРАДАВШИХ ОТ DK}

Терапия для DK имеет две различные цели в зависимости от стадии, в которой она находится. В острой фразе, она направлена на снижение воспалительной реакции в стенке коронарной артерии и предотвратить васкулит и его последствия (тромбоз и аневризмы). В подострых и хронических фразах, цель состоит в том, чтобы предотвратить ишемию миокарда и инфаркт (CASTRO; URBANO; COSTA, 2009).

Внутривенный иммуноглобулин (IGEV) является основным лекарством, используемым в DK и его механизм действия остается неизвестным. Он используется в острой фазе, предпочтительно в первые 7-10 дней начала состояния (MAGALHÃES; ALVES, 2017).

Лечение состоит из введения иммуноглобулина в разовой дозе 2 г/кг в течение переменного периода от 10 до 12 часов вместе с применением ацетилсалициловой кислоты (AAS) от 80 до 100 мг/кг/день, устно, 6/6 часов. Высокая доза AAS имеет противовоспалительное действие и, в низких дозах, действует как ингибитор агрегации тромбоцитов, так что время использования AAS в высоких дозах должно оставаться до тех пор, пока ребенок не будет афебрил. Затем доза уменьшается до 3 до 5 мг/кг/день и поддерживается в

RC: 82509

Disponível

em: https://www.nucleodoconhecimento.com.br/здравоохранение/болезнь- 
этой дозе, в то время как пациент представляет тромбоцитоз и/или коронарные изменения (MAGALHÃES; ALVES, 2017; RODRIGUES et al., 2017).

От 1 до 2 из 10 пациентов с DK не реагируют на первую дозу IGEV, или с перманентностью лихорадочное состояние или с появлением его через полтора дня после первого вливания. Эти пациенты считаются огнеупорными для лечения и являются теми, с самым высоким риском коронарных изменений. В таких случаях рекомендуется введения второй дозы IGEV 2 г/кг в разовой дозе. Если лихорадка сохраняется в течение 36 часов, рекомендуется использовать импульсную терапию метилпреднизолоном в дозе 30 мг/кг/день (максимальная доза 1 г/день), пронизанная в 1 час, 1 раз/день, в течение 3 дней (MAGALHÃES; ALVES, 2017).

При лечении DK в подостраховой и хронической фразах низкодозный аспирин (35 мг/кг/день) используется у детей с малыми и средними аневризмами. На этих этапах лечение направлено на предотвращение тромбоза (активации тромбоцитов) и протезирования сосудов. Другие антитромбоцитаные средства также используются (клопидогрель, тиклопидин, дипиридамол) и, связанные с аспирин, представляются как более конкретные в блокировании агрегации тромбоцитов (CASTRO; URBANO; COSTA, 2009).

\section{ОБСУЖДЕНИЯ}

\section{КОРРЕЛЯЦИЯ МЕЖДУ ВОЗМОЖНЫМИ КАУСАТОРАМИ И РАЗВИТИЯ DK}

На сегодняшний день происхождение DK не установлено, но есть некоторые агенты, которые, как полагают, связаны с развитием патологии. Это золотистый Staphylococcus aureus, estreptococos, вирус гриппа, morbilivírus, paramixovírus, bunyavírus. Аденовирус и новый коронавирус

RC: 82509

Disponível

em: https://www.nucleodoconhecimento.com.br/здравоохранение/болезнь- 
человека под названием New Haven коронавирус (Nco-NH) также могут быть связаны с DK, так как они уже были выявлены в дыхательных путей выделения пациентов с этим заболеванием. Такие вирусы и бактерии могут повлиять на развитие DK, так что они приведут к данным, вызванным болезнью, таким как аневризмы аорты (BARCA et al., 2019; CASTRO; URBANO; COSTA, 2009).

Существует гипотеза, которая связывает существование бактериальных суперантигенов с развитием DK. Исследования, анализирующие это предложение предположить, что суперантиген может связываться с антигенпредставления клеток, через класс II основных гистосовместимости комплекса (класс II MHC) и Т-лимфоцитов рецепторов на связывающих участках отличается от общих антигенов. Это способствовало бы иммунологической реакции с образованием и высвобождением провоспалительных цитокинов в чрезмерных концентрациях, способствуя эволюции воспалительного процесса, характерного для DK (CASTRO; URBANO; COSTA, 2009).

Некоторые признаки приводят к считает, что олигоклональный $\lg A$ ответ происходит в острой DK. Исследование, проведенное Castro, Urbano и Costa (2009) провел анализ альфа-тяжелой цепи иммуноглобулинов, собранных из большого количества лейкоцитов, накопленных в месте воспалительной реакци артериальной стенки пациентов с DK, который показал, что в образце были обнаружены специфические иммуноглобулин A $(\lg A)$. Это свидетельствует о существовании иммунного ответа, связанного с DK (CASTRO; URBANO; COSTA, 2009).

Гипотеза о том, что DK имеет генетическую предрасположенность усиливается высокой заболеваемостью среди азиатов и их рыться. Одно исследование показало 67 генов, связанных с развитием патологии, которая включала участие в эндотелии, метаболизме липидов, активации иммунологических механизмов и наборе тромбоцитов, поддерживая идею о том, что существует

RC: 82509

Disponível

em: https://www.nucleodoconhecimento.com.br/здравоохранение/болезнь- 
генетическая связь для развития DK (CASTRO; URBANO; COSTA, 2009; SOTELO; GONZÁLEZ, 2007).

\section{ФИЗИОПАТИЯ DK}

Васкулит начинается с возникновения отеков и воспалений, которые могут возникать в течение переменного периода. Нейтрофрилов присутствуют на начальном этапе, и вскоре после этого преобладает цитотоксические Тлимфоциты CD8+ и иммуноглобулин IgA (CASTRO; URBANO; COSTA, 2009).

В коронарных артериях происходят воспалительные изменения с наличием отеков и некроза мышечных клеток. С этой потерей структурной целостности существует образование аневризм. Кроме того, фибробласты размножаются, а затем переделывать, что приводит к возможному наличию сустеза, кальцификации и тромбоза (CASTRO; URBANO; COSTA, 2009; SOTELO; GONZÁLEZ, 2007).

Важно отметить, что воспалительный фрактор 1 , обнаруженный в алотрансплантатах, резко увеличивается в шимнотических артериальных тканях DK. Этот воспалительный фрактор 1 авлотрансплантата связывает реакцию интерферона типа I до активации конкретных макрофрагов и Тлимфоцитов, что предполагает вероятную важность вмешательства этих клеток в артериит DK (ROWLEY et al., 2017).

\section{КАК ОСНОВНЫЕ ОРГАНЫ И АНАТОМИЧЕСКИЕ СТРУКТУРЫ СТРАДАЮТ ОТ DK}

DK воздействует на органы и артерии, в основном на сосуды среднего размера, такие как сосуды сердца, в частности коронарные артерии, с образованием аневризм. Болезнь может также повлиять на дыхательную систему (легкие),

RC: 82509

Disponível

em: https://www.nucleodoconhecimento.com.br/здравоохранение/болезнь- 
через васкулит, желудочно-кишечного тракта, в основном кишечника и желчного пузыря, и нервной системы (CASTRO; URBANO; COSTA, 2009).

Лимфратическая система может быть затронута DK, так как одним из симптомов DK является отек лимфатических узлов шейки матки. Кожная система повреждена кожной эритемой, за которой следуют отеки. В глазах может возникнуть непутивная конъюнктивная гиперемия и слизистые оболочки полости рта могут быть поражены слизистой оболочкой рта и поражениями на губах (SOTELO; GONZÁLEZ, 2007).

\section{ОСНОВНЫЕ ХАРАКТЕРИСТИКИ КЛИНИЧЕСКОЙ КАРТИНЫ ЧЕЛОВЕКА С DК И КАК ОНИ ВЛИЯЮТ НА НЕГО}

Клинический курс DK можно разделить на три клинические стадии: острую, подостраливую и выздоровление. Острая лихорадочная стадия обычно длится от 7 до 14 дней, характеризуется конъюнктурными заторами, оральным мукозитом, эритемой, шелушением и полиморфной сыпью и лимфаденопатией. Пододолтной стадией является период между окончанием лихорадки и 25-м днем заболевания. На данном этапе пациенты, присутствующие с шелушение кожи в конечностях, артрит, артралгия и тромбоцитоз. Стадия выздоровления начинается, когда клинические симптомы начинают исчезать и продолжается до нормального установления VHS (красный уровень кровяного давления), который обычно наблюдается от 6 до 8 недель после появления симптомов. Такие этапы влияют на жизнь пациента, так как они мешают ему выполнять свою повседневную деятельность, которая в основном из-за поражений кожи и симптоматологии (ALMEIDA, 2017; SCARDINA et al., 2007).

Состояние наводящий патологии характеризуется лихорадкой, увеличением лимфатических узлов шейки матки и тонзиллитом, а затем обобщенной кожной эритемой, зудом и отеком конечностей и после нескольких дней шелушения.

RC: 82509

Disponível

em: https://www.nucleodoconhecimento.com.br/здравоохранение/болезнь- 
Лабораторные тесты показывают активную воспалительную фразу с высокой скоростью осаждения, С-реактивным белком, лейкоцитозом и увеличением количества тромбоцитов, что приводит к летаргии пострадавшего человека, так как воспаление может вызвать сильную боль (ALMEIDA, 2018; ATIK; FORONDA; BUSTAMANTE, 2003; FERRONATO et al., 2010; ROSSI et al., 2015).

Может возникнуть непутивная конъюнктурная гиперемия; макулярная папулярная сыпь; поражения губ и полости рта; изменения кожи конечностей, помимо предучительного ропота, затрудненное дыхание, боли в животе, дисурия, гепатомегалия, артралгия, застыние шеи и судороги. Эти симптомы мешают пациенту видеть и получать вокруг нормально, в виду того что глаза повреждены и боль причиняет затруднение, для того чтобы выполнить движения (CASTRO; URBANO; COSTA, 2009; SOTELO; GONZÁLEZ, 2007).

DK поражает несколько пациентов с васкулитом в различных органах, как было сказано ранее, легких, кишечника, желчного пузыря, центральной нервной системы, являются примером, что приводит к появлению таких симптомов, как усталость, потеря веса и боль в суставах и мышцах, но повреждение сердца является наиболее значительным, с образованием коронарных аневризм, которые приводят к стенокардии (CASTRO; URBANO; COSTA, 2009; PRINTZ, 2011).

Другим симптомом является раздражение, которое появляется у детей с этим заболеванием, и желудочно-кишечные жалобы, в том числе диарея, рвота и боли в животе, возникают примерно у одной трети пациентов, что объясняет тот фракт, что дети с DK более раздражены, чем другие (ALMEIDA, 2018; KAYIRAN; DINDAR; GURAKAN, 2010).

Абсцесс и ретрофрарингальный отек, как правило, связаны со смертельным состоянием, если не лечить должным образом. Оториноларингологи могут

RC: 82509

Disponível

em: https://www.nucleodoconhecimento.com.br/здравоохранение/болезнь- 
лечить его хирургическим дренажем абсцесса, предотвращая блок дыхательных путей (KIM; KWON, 2016; XIE et al., 2018).

Оральный мукозит представлен дифффузной эритемой слизистой оболочки, покраснением в губах и языке, а также гипертрофией лингвального сосочки с последующим развитием клубничного языка, и обычно происходит в острой стадии заболевания и выздоровления, как следствие фрармакологического лечения, и предотвращает правильное кормление пациента из-за поражений, влияющих на его адекватное питание (SCARDINA et al., 2007).

\section{ДИАГНОЗ DK}

DK представляет собой проблему, которая будет диагностирована на ранней стадии, так как это необычное ревматологическое расстройство, которое требует конкретного вмешательства, чтобы избежать серьезных или смертельных сиквелов (ALMEIDA et al., 2010).

Клиника заболевания неясна, является общим первоначальный диагноз других заболеваний, таких как скарлатина, вирусные экзантемы или аллергические состояния, в связи с первоначальными симптомами заболевания. Даже при полном выполнении критериев часто задерживается правильный диагноз, что приводит к задержке в начале соответствующего лечения, благоприятствуя появлению осложнений, которые могут быстро усугубить клиническое состояние пациента. Кроме того, существуют неполные или нетипичные формы, которые делают диагностику еще более сложной. Ранняя диагностика заболевания важна, так как лечение в острой фразе снижает воспалительный процесс в коронарных артериях и предотвращает тромбоз, снижая шансы на смертность (FERRONATO et al., 2010).

RC: 82509

Disponível

em: https://www.nucleodoconhecimento.com.br/здравоохранение/болезнь- 
Своевременная клиническая диагностика имеет важное значение для установления этого раннего лечения и избежать коронарных поражений. Этот тип травмы может вызвать ишемию или инфаркт миокарда, который является чрезвычайно тяжелым (KAYIRAN; DINDAR; GURAKAN, 2010; SOTELO; GONZÁLEZ, 2007).

Диагностическими критериями классической болезни DK являются лихорадка с пятью днями или более, в дополнение к по крайней мере четырем другим критериям, которые: пальмоплантарная эритема с или без болезненных отеков или периунигеального шелушения; Полиморфная экзатема; бульбарная конъюнктива гиперемия с обеих сторон, а не экссудативная; Изменения в губах и слизистой оболочке полости рта; Лимфаденопатия шейки матки - диаметр более 1,5 cм, твердый и безболезненный при пальпации. Диагноз неполного DK может быть установлен в присутствии трех или более из следующих критериев: Альбумин $\leq 3 \mathrm{~g} / \mathrm{dL} ;$ Анемия; Подъем аминотрансферазы аланина; Тромбоциты

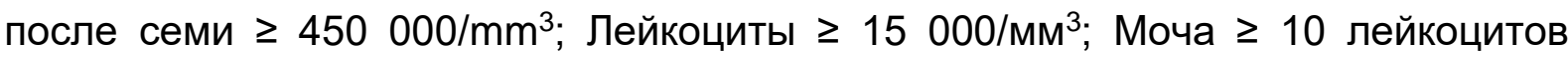
(CASTRO; ГОРОДСКИЕ; КОСТА, 2009; РОДРИГЕС и др., 2017; YAР; LIN; WANGUI, 2012).

Основные сиквелы заболевания связаны с сердечной системой, поэтому сердечная визуализация с помощью эхокардиографии является актуальной частью оценки пациентов с подозрением на DK. При диагностике рекомендуется эхокардиография при постановке диагноза через 6-8 недель после начала заболевания (ATIK et al., 2017; KAYIRAN; DINDAR; GURAKAN, 2010)

Наиболее частыми лабораторными изменениями являются анализ крови с лейкоцитозом и нейтрофилией, в дополнение к увеличению значений острых фазовых тестов, таких как скорость гемоседиментации и С-реактивный белок.

RC: 82509

Disponível

em: https://www.nucleodoconhecimento.com.br/здравоохранение/болезнь- 
Заболевание часто диагностируется только после участия в коронарной артерии (FERRONATO et al., 2010).

Исследование, проведенное Kentsis et al. (2013) обнаружили, что фриламин C и мефрина маркеры были обнаружены в сыворотке крови и моче двух независимых групп участвующих пациентов DK. То же исследование находит использование этих маркеров для выполнения диагностики DK как более эфффективным, чем использование маркеров в настоящее время используется (KENTSIS et al., 2013).

\section{ЭКЗАМЕНЫ ИЗОБРАЖЕНИЯ И ДОПОЛНИТЕЛЬНЫЕ}

Эхокардиограмма является одним из основных тестов, используемых для диагностики DK, так как она не является инвазивной, имеет высокую чувствительность и специфичность для анализа и выявления аномалий в коронарных артериях, оценки миокарда и проверки наличия перикардита. В этом исследовании могут появиться некоторые выводы, указывающие на коронарный артерит, который предшествует образованию аневризм, таких как перивазкулярная яркость, эстазия или сужение коронарных артерий. При анализе коронарных артерий следует оценить внутренний диаметр сосуда; количество, местоположение и тип (будь то саккулярные или фрузиформные) аневризм; и наличие или не наличие внутрисветового тромба и сустеза. В острой фразе заболевания, некоторые частые выводы в эхокардиограммы являются: снижение контрактности левого желудочка, регургитация митрального клапана и перикардиального выпота (CASTRO; URBANO; COSTA, 2009; MAGALHÃES; ALVES, 2017; RODRIGUES et al., 2017).

Другие тесты, которые могут быть выполнены, в зависимости от наличия, тяжести, преимуществ и показаний, которые варьируются в зависимости от случая. Например, магнитно-резонансная томография (RNM), ангиоресонанс,

RC: 82509

Disponível

em: https://www.nucleodoconhecimento.com.br/здравоохранение/болезнь- 
рентген грудной клетки, компьютерная томографрия высокого разрешения, ангиография (CASTRO; URBANO; COSTA, 2009).

КТ ангиография, инвазивное обследование, которое имеет риски, и ангиоресонанс, как правило, выполняются у тех пациентов, которые представили аномалии на электрокардиограмме, эхокардиографические или симптомы ишемии миокарда (CASTRO; URBANO; COSTA, 2009; MAGALHÃES; ALVES, 2017).

В последнее время компьютерная томография с высоким разрешением была более показана, особенно по сравнению с RNM, так как еe выполнение происходит быстрее и проще в интерпретации, в то время как RNM требует более длительного анестезического времени детей для сбора (CASTRO; URBANO; COSTA, 2009).

Рентген грудной клетки, который обычно не представляет изменений, примерно в $15 \%$ случаев обнаруживаются аномалии, такие как: паттерн стикулогранулярного или перибрончиального проникновения, накопление слишком большого количество жидкости в пространстве между висцеральным и теменной плеврами или коллапс легких. Они появляются после 10-го дня заболевания и могут проверить на рентгенографии от 10 до 50 дней после начала состояния (CASTRO; URBANO; COSTA, 2009).

В лабораторных испытаниях, выводы не являются специфическими для DK, a скорее свидетельствует о высоком воспалительном процессе, и можно найти, в начале острой фразы, увеличение скорости гемоседиментации (VHS), Cреактивный белок (PCR) и кислоты альфагликопротеин ставки. В анализе крови можно проверить аномально большое количество нейтрофилов, называемых лейкоцитозом с нейтрофилией, и может сопровождаться увеличением летучих мышей или эозинофилии. Кроме того, количество тромбоцитов, как правило,

RC: 82509

Disponível

em: https://www.nucleodoconhecimento.com.br/здравоохранение/болезнь- 
нормально в острой фразе, однако, вполне возможно, что в некоторых случаях есть тромбоцитопения, которая связана с развитием тяжелой ишемической болезни и инфаркта миокарда (MAGALHÃES; ALVES, 2017).

\section{АНАЛИЗ ОСНОВНЫХ ОСЛОЖНЕНИЙ, СВЯЗАННЫХ С DK}

Наиболее серьезным осложнением заболевания является коронарный васкулит, который поражает 15-20\% необработанных пациентов, что может привести к аневризме, эстазии и сустезу коронарных артерий, на которые приходится 2\% смертности. Другие осложнения DK были описаны как аневризмы в других артериях, таких как аорта; брюшной аорты; подмысоляя артерия; брахиоцефалическая артерия; подвздошные артерии, бедренные артерии и почечные артерии, что указывает на то, как DK может значительно повлиять на организм человека, и, таким образом, быть чрезвычайно опасным (ALVES, et al., 2011; CHBEIR et al., 2018; MUTLUER; ÇELIKER, 2019; PRINTZ, 2011; XIE et al., 2018).

Некоторые пациенты с DK подвержены прогрессирующему коронарного расширения. Такое расширение коронарной артерии происходит во время острой фразы и может перейти к подоздной фразе, что усугубляет клиническое состояние нескольких пациентов (BRIEDÉ et al., 2015; 2015; LIU et al., 2017).

Желудочно-кишечные осложнения в DK могут возникнуть, такие как кишечная непроходимость, отек толстой кишки, ишемия кишечника, кишечная псевдообструкция, и острый живот, который влияет на пациента тревожно, так как эти осложнения могут привести к сепсису и даже смерти. Кроме того, офртальмологические изменения, связанные с DK может включать увеит, иридоциклит, конъюнктивальное кровоизлияние, зрительный неврит, амауроз, и обструкция глазной артерии, которая вызывает непоправимое продолжение

RC: 82509

Disponível

em: https://www.nucleodoconhecimento.com.br/здравоохранение/болезнь- 
несколько раз. DK также проявляется как некротизирующий васкулит, что приводит к потере пораженной ткани (ALVES, et al., 2011).

Неврологические осложнения из-за травмы SNC могут быть следующими: менингоэнцефалит, субдуральный сбор, гипоперфузия головного мозга, ишемия, инфаркт головного мозга, судороги, эмиплегия, психическое замешательство, вялость и даже кома или инфраркт головного мозга. Такие осложнения могут стать необратимыми, тем самым навсегда нанося вред жизни пациента (ALVES, et al., 2011).

Риск поздних осложнений DK свидетельствует о необходимости долгосрочного последующего развития в дополнение к детству (GIACCHI et al., 2014).

\section{ЛЕЧЕНИЕ ДЛЯ ЛИЦ, ПОСТРАДАВШИХ ОТ DK}

Наиболее распространенным методом лечения является применение IGIV (внутривенный иммуноглобулин) в разовой дозе 2 г/кг на 12-часовой инфузии. В соответствии с эволюцией клинического кваро пациента, доза IGIV может быть повторена или кортикостероиды могут быть добавлены, особенно в огнеупорных случаях. Рекомендуются другие препараты, такие как циклофоссрамид, циклоспорин и улинастатин. Также рекомендуется продукт, основанный на моноклональных антителах против фрактора некроза опухоли альфа, а также моноклональные антитела, известные как Abciximab, которые могут лечить аневризмы быстрее (ATIK, 2007; FERRONATO et al., 1010; KAYIRAN; DINDAR; GURAKAN, 2010; PHILIP et al., 2017; SOTELO; GONZÁLEZ, 2007).

Приблизительно от 10 до 15\% пациентов с DK не показывают никаких улучшений с лечением IGIV, которое является стандартным лечением (MEHNDIRATTA et al., 2014). У педиатрических пациентов с DK высокие дозы

RC: 82509

Disponível

em: https://www.nucleodoconhecimento.com.br/здравоохранение/болезнь- 
ацетилсалициловой кислоты (AAS) обеспечивают противовоспалительное действие, в то время как низкие дозы оказывают ингибирующее действие агрегации тромбоцитов. Так, в острой фразе заболевания используется AAS 80100 мг/кг/день, который делится на четыре ингестии в течение дня, чтобы усилить противовоспалительное действие IGIV. Если в некоторых больницах доза AAS снижается через 2-3 дня при отсутствии лихорадки, то в других медицинских центрах лечение продолжается до 2 недель. Кроме того, дети с сердечными нарушениями имеют рецепт на слух аас на неопределенный срок (ATIK, 2007; CASTRO; URBANO; COSTA, 2009; MEHNDIRATTA et al., 2014).

Иммуносупрессивные препараты, такие как циклофросфамид также используются, вместе с преднизолоном или метилпреднизолоном, для улучшения некоторых симптомов, таких как лихорадка, но эти лекарства не имеют терапевтического влияния на сердечные аномалии (CASTRO; URBANO; COSTA, 2009; PHILIP et al., 2017).

В острой фразе заболевания DK существует более высокий хирургический риск, поскольку при наличии воспаления анатомоз с воспаленной коронарной артерией рискует обструкции. Хирургический подход должен быть ограничен пациентами с гигантскими аневризмами или ишемическими процессами после острой фразы (ATIK, 2007; SOTELO; GONZÁLEZ, 2007).

Хирургическая реваскуляризация коронарных поражений, вторичных по отношению к DK, является относительно редкой. В соответствии с действующими руководящими принципами, полная артериальная реваскуляризация должна использоваться у молодых пациентов с небольшими сопутствующими заболеваниями для получения хорошей проницаемости для долгосрочного трансплантата (BARCA et al., 2019).

$\mathrm{RC}: 82509$

Disponível

em: https://www.nucleodoconhecimento.com.br/здравоохранение/болезнь- 
В дополнение к операции по реваскуляризации миокарда, которая является методом выбора при тромботических коронарных осложнениях DK, чрескожное коронарное вмешательство (ICP) с использованием обычных или чрескожных стентов с политетрафторэтиленом (PTFE), имплантация спирали, чрескожная транслюминальная реваскуляризация коронарных артерий (PTCR) с применением тромболитических агентов в артерии, связанной с инфарктом, и чрескожная коронарно-ротационная абляция (PTCRA) использовались у пациентов, страдающих этим заболеванием (MUTLUER; ÇELIKER, 2019).

Что касается анестезии управления, мало информации, описанной, однако, миокарда реваскуляризации с анестезией осуществляется галогенных газов представляет меньший ущерб, тем самым показывая лучшее послеоперационное восстановление функции миокарда по сравнению с внутривенной анестезии. Таким образом, он способствует ингибированию нейроэндокринной реакции на стресс, а также готовит пациента к раннему экстубации в послеоперационный период, что помогает в профрилактике возможных осложнений, возникающих в результате интубации (MARTÍNEZ; MÉNDEZ, 2013).

\section{ЗАКЛЮЧЕНИЕ}

Возникновение DK является переменным, в большей раз присутствует в азиатском регионе, особенно у детей в возрасте до 5 лет. В Латинской Америке заболеваемость встречается реже, а смертность от этой патологии низкая.

Этиологический агент DK не был выявлен, но есть некоторые патогенные микроорганизмы, которые могут быть связаны с этим заболеванием. Существует доказательство того, что это заболевание имеет генетическую связь, это было установлено в связи с увеличением заболеваемости среди

RC: 82509

Disponível

em: https://www.nucleodoconhecimento.com.br/здравоохранение/болезнь- 
азиатских людей и среди родственников пациентов, пострадавших от DK, кроме того, Есть также некоторые гены, которые связаны с этой патологией.

Есть изменения, связанные с DK, такие как системные воспаления, затрагивающие определенные органы, вызванные ангиит, стерильный менингит, пневмонит, аденофинит и гепатит. DK воздействует на органы и артерии, в основном среднекалиберных сосудов, таких как сосуды сердца, так что приводит к образованию аневризм, может повлиять на глаза, слизистые оболочки полости рта, легких, кишечника, желчного пузыря и нервной системы, лимфатической системы, системы кожи и поражения могут возникнуть в губах.

Клиническая картина DK имеет три этапа. Острая фребрильная стадия характеризуется конъюнктивальным затором, оральным мукозитом, эритемой, шелушением, полиморфной сыпью и боковой лимфаденопатией. Подострая стадия происходит в конце лихорадки, пациенты кожи шелушение на конечностях, артрит, артралгия и тромбоцитоз. Стадия выздоровления возникает, когда симптомы почти исчезают и продолжаются до их нормализации.

Задержка с правильной диагностикой DK довольно часто, что может привести к задержке в начале лечения, что может привести к осложнению ухудшить клиническое состояние. Ранняя клиническая диагностика чрезвычайно важна для установления раннего лечения и избежать травм коронарных артерий.

Лечение DK основано на эволюции клинической картины пациента. Наиболее часто используемой терапией является применение IGIV, если в клинике происходят изменения, доза IGIV может быть повторена или кортикостероиды могут быть добавлены. Другие лекарства могут быть указаны, такие как циклофросфрамид, циклоспорин, и ulinastatin. Рекомендуется также продукт на основе моноклональных антител Infliximab, иммунодепрессанты, такие как

RC: 82509

Disponível

em: https://www.nucleodoconhecimento.com.br/здравоохранение/болезнь- 
циклофосфамид или циклоспорин и преднизон или метилпреднизолон может быть использован. Хирургическое лечение делается в основном в острой фазе DK, но должно быть ограничено пациентами с гигантскими аневризмами или ишемическими процессами после острой фразы заболевания.

\section{ссылки}

ALMEIDA, F. C. Avaliação das manifestações clínicas e achados laboratoriais em 301 pacientes com doença de Kawasaki: acompanhamento de dez anos. Tese (Doutorado em Ciências Médicas). Faculdade de Medicina, Universidade de Brasília, Brasília. 2018.

ALMEIDA, M. A. A. L. S. Avaliação da calprotectina e dos anticorpos anticitoplasma de neutrófilos como marcadores de inflamação e autoimunidade nas diferentes fases da doença de Kawasaki. Dissertação (Mestrado em Ciências Farmacêuticas). Faculdade de Ciências da Saúde, Universidade de Brasília, Brasília. 2017.

ALMEIDA, R. G. et al. Perfil da doença de Kawasaki em crianças encaminhadas para dois serviços de reumatologia pediátrica do Rio de Janeiro, Brasil. Revista Brasileira de Reumatologia, v. 50, n. 5, p. 529-538, set./out. 2010.

ALVES, N. R. M. et al. Estudo prospectivo das complicações da Doença de Kawasaki: análise de 115 casos. Revista da Associação Médica Brasileira, v. 57, n. 3, p. 299-305, mar. 2011.

ATIK, E. Doença de Kawasaki: Regressão de Aneurismas Gigantes das Artérias Coronárias com Obstrução Tardia Posterior Kawasaki Disease: Giant Coronary Arteries Aneurysms Regression and Later Stenosis. Arquivos brasileiros de Cardiologia, v. 88, n. 1, p. 22-23, 2007.

$\mathrm{RC}: 82509$

Disponível

em: https://www.nucleodoconhecimento.com.br/здравоохранение/болезнь- 
ATIK, E.; FORONDA, A.; BUSTAMANTE, L. N. P. Kawasaki Disease. Involution of Giant Coronary Aneurysms After Prolonged Anti-inflammatory Treatment. Arquivos brasileiros de Cardiologia, v. 81, n. 3, p. 265-72, set. 2003.

ATIK, E. et al. Caso 6/2017 - Extenso Aneurisma Gigante de Artéria Coronária Esquerda por Vasculite de Kawasaki em Homem Assintomático com 48 Anos de Idade. Arquivos brasileiros de Cardiologia, v. 109, n. 5, p. 489-490, nov. 2017.

BARCA, L. V. et al. Ligature of the Left Main Coronary Artery after Surgery in Kawasaki Disease: Case Report. Braz J Cardiovasc Surg, v. 34, n. 1, p. 111-113, jan./fev., 2019.

BRIEDÉ, S. et al. Hamoen M, Oosterveld M JS, Breur JMPJ. Langetermijneffecten van de ziekte van Kawasaki. Ned tijdschr geneeskd, v. 154, n. 2121, p. 1-6, out. 2015.

CASTRO, P. A.; URBANO, L. M. F.; COSTA, I. M. C. Doença de Kawasaki. Anais Brasileiros de Dermatologia, v. 84, n. 4, p. 317-331, mai. 2009.

CHBEIR, D. et al. Kawasaki disease: abnormal initial echocardiogram is associated with resistance to IV $\lg$ and development of coronary artery lesions. Pediatric Rheumatology Onlinw Journal, v. 6, n. 48, p. 1-10, jul. 2018.

FERRONATO, A. E. et al. Doença de Kawasaki: experiência clínica em hospital universitário. Revista Paulista de Pediatria, v. 28, n. 2, p. 148-154, jun. 2010.

GIACCHI, V. et al. Avaliação do espessamento íntimo da artéria coronária em pacientes com diagnóstico prévio de doença de Kawasaki por meio de ecocardiografia transtorácica de alta resolução: nossa experiência. BMC Cardiovasc Disord, v. 14, n. 106, p 1-6, ago. 2014.

RC: 82509

Disponível

em: https://www.nucleodoconhecimento.com.br/здравоохранение/болезнь- 
HUANG, X. et al. Influenza infection and Kawasaki disease. Revista da Sociedade Brasileira de Medicina Tropical, v. 48, n. 3, p. 243-248, jun. 2015.

KAYIRAN, S. M.; DINDAR, A. N.; GURAKAN, B. An evaluation of children with Kawasaki disease in Istanbul: a retrospective follow-up study. Clinical Science, v. 65, n. 12, p. 1261-1265, dez. 2010.

KENTSIS, A. et al. Urine proteomics for discovery of improved diagnostic markers of Kawasaki disease. EMBO Mol Med, v. 5, n. 2, p. 210-220, fev. 2013.

KIM, J. S.; KWON, S. H. Atypical Kawasaki disease presenting a retropharyngeal abscess. Braz J Otorhinolaryngol, v. 82, n. 4, p. 484-486, 2016.

LIU, M. Y. et al. Risk factors and implications of progressive coronary dilatation in children with Kawasaki disease. BMC Pediatrics, v. 17, n. 139, p. 1-7, jun. 2017.

MAGALHÃES, C. M. E. Estudo da prevalência da perda auditiva neurossensorial como complicação da doença de Kawasaki. Tese (Doutorado em Ciências da Saúde) - Faculdade de ciências da saúde, Universidade Federal de Brasília, Brasília. 2008.

MAGALHÃES, C. M. R.; ALVES, N. R. M. Doença de Kawasaki. In: I. Burns, DAR, Campos Júnior D, Silva LR, Borges WG. Tratado de pediatria: Sociedade Brasileira de Pediatria. 4. ed. Barueri, SP: Manole, 2017. p.1825-1835.

MARTÍNEZ, U. M.; MÉNDEZ, F. M. Manejo anestésico del paciente com enfermedad de Kawasaki durante la cirugía de revascularización coronaria: informe de um caso. Archivos de Cardiología de México, v. 83, n. 4, p. 267-272, abr. 2013.

$\mathrm{RC}: 82509$

Disponível

em: https://www.nucleodoconhecimento.com.br/здравоохранение/болезнь- 
MEHNDIRATTA, S. et al. A case of incomplete and refractory Kawasaki disease: Diagnostic and therapeutic challenges. The South African Journal of Child Health, v. 8, n. 1, p. 37-38, fev. 2014.

MUTLUER, F. O.; ÇELIKER, A. Comment on Ligature of the Left Main Coeonary Artery after Surgery in Kawasaki Disease: Case Report. Brazilian Journal of Cardiovascular Surgery, v. 34, n.3, p. 382, jul. 2019.

PHILIP, S. et al. Role of Antioxidants in Horse Serummediated Vasculitis in Swine: Potential Relevance to Early Treatment in Mitigation of Coronary Arteritis in Kawasaki Disease. Pediatrics and Neonatology, v. 58, n. 4, p. 328-337, fev. 2017.

PRINTZ, B. F. Noncoronary Cardiac Abnormalities Are Associated With Coronary Artery Dilation and With Laboratory Inflammatory Markers in Acute Kawasaki Disease. Journal of the American College of Cardiology, v. 57, n. 1, p. 68-92, jan. 2011.

RODRIGUES, M. et al. Doença de Kawasaki e Complicações Cardiovasculares em Pediatria. Birth and growth medical jornal, v.27, n. 1, p. 54-58, fev. 2017.

ROSSI, F. S. et al. Extensa linfadenite cervical mimetizando adenite bacteriana como primeira manifestação da doença de Kawasaki. Einstein, v. 13, n. 3, p. 426429, jul./set. 2015.

ROWLEY, A. H. et al. Allograft Inflammatory Factor-1 Links T-Cell Activation, Interferon Response, and Macrophage Activation in Chronic Kawasaki Disease Arteritis. Journal of the Pediatric Infectious Diseases Society, v. 6, n. 3, p. 94102, set. 2017.

RC: 82509

Disponível

em: https://www.nucleodoconhecimento.com.br/здравоохранение/болезнь- 
SCARDINA, G. A. et al. Oral necrotizing microvasculitis in a patient affected by Kawasaki disease. Medicina Oral Patologia Oral y Cirugia Bucal, v. 12, n. 8, p. 560-564, dez. 2007.

SOTELO, N.; GONZÁLEZ, L. A. Kawasaki disease: A rare pediatric pathology in Mexico Twenty cases report from the Hospital Infantil del Estado de Sonora. Archivos de Cardiologia de Mexico, v. 77, n. 4, p. 299-307, dez. 2007.

XIE, X. F. et al. Proteomics study of serum exosomes in Kawasaki disease patients with coronary artery aneurysms. Cardiology Journal, v. 26, n. 5, p. 584-593, fev. 2018.

YAP, C. Y.; LIN, L. H.; WANGI, N. K. An atypical presentation of Kawasaki disease: a 10- year-old boy with acute exudative tonsillitis and bilateral cervical lymphadenitis. CLINICS, v. 67, n. 6, p. 689-692, 2012.

Представлено: Апрель 2021 года.

Утверждено: Апрель 2021 года.

RC: 82509

Disponível em: https://www.nucleodoconhecimento.com.br/здравоохранение/болезнь- 